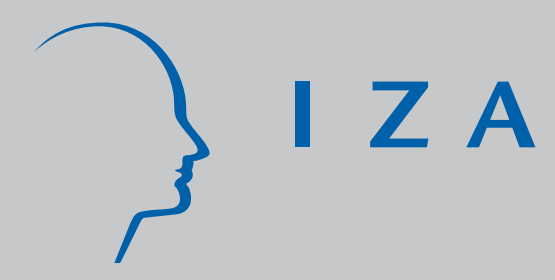

IZA DP No. 3188

Non-Cognitive Child Outcomes and Universal High Quality Child Care

Nabanita Datta Gupta

Marianne Simonsen

November 2007 


\title{
Non-Cognitive Child Outcomes and Universal High Quality Child Care
}

\author{
Nabanita Datta Gupta \\ Danish National Centre for Social Research \\ and IZA \\ Marianne Simonsen \\ University of Aarhus
}

Discussion Paper No. 3188

November 2007

\author{
IZA \\ P.O. Box 7240 \\ 53072 Bonn \\ Germany \\ Phone: +49-228-3894-0 \\ Fax: +49-228-3894-180 \\ E-mail: iza@iza.org
}

\begin{abstract}
Any opinions expressed here are those of the author(s) and not those of the institute. Research disseminated by IZA may include views on policy, but the institute itself takes no institutional policy positions.

The Institute for the Study of Labor (IZA) in Bonn is a local and virtual international research center and a place of communication between science, politics and business. IZA is an independent nonprofit company supported by Deutsche Post World Net. The center is associated with the University of Bonn and offers a stimulating research environment through its research networks, research support, and visitors and doctoral programs. IZA engages in (i) original and internationally competitive research in all fields of labor economics, (ii) development of policy concepts, and (iii) dissemination of research results and concepts to the interested public.
\end{abstract}

IZA Discussion Papers often represent preliminary work and are circulated to encourage discussion. Citation of such a paper should account for its provisional character. A revised version may be available directly from the author. 
IZA Discussion Paper No. 3188

November 2007

\section{ABSTRACT}

\section{Non-Cognitive Child Outcomes and Universal High Quality Child Care*}

Exploiting a rich panel data child survey merged with administrative records along with a pseudo-experiment generating variation in the take-up of pre-school across municipalities, we provide evidence of the effects on non-cognitive child outcomes of participating in large scale publicly provided universal pre-school programs and family day care vis-à-vis home care. We find that, compared to home care, being enrolled in pre-school at age three does not lead to significant differences in child outcomes at age seven no matter the gender or mother's level of education. Family day care, on the other hand, seems to significantly deteriorate outcomes for boys whose mothers have a lower level of education. Finally, increasing hours in family day care from 30-40 hours per week to 40-50 hours per week and hours in pre-school from 20-30 hours per week to 30-40 hours per week leads to significantly poorer child outcomes.

JEL Classification: J13, J18

Keywords: non-cognitive outcomes, publicly provided universal child care, pseudo-experiment

Corresponding author:

Nabanita Datta Gupta

Danish National Centre for Social Research

Herluf Trolles Gade 11

DK-1052 Copenhagen K

Denmark

E-mail: ndg@sfi.dk

\footnotetext{
* Access to the Danish Longitudinal Survey of Children was granted us by the Danish National Centre for Social Research. We are thankful to Mette Lausten for data assistance and to Niels Glavind from Bureau 2000 for supplying crucial information on child care guarantees. We would like to thank Joseph J. Doyle, David Friswold, Helena Skyt Nielsen, Jeff Smith, and Astrid Würtz for helpful comments. The paper has also benefited from comments received at the University of Michigan Labor Group Workshop, the ISR quantitative methods program workshop, the School of Economics and Management at University of Aarhus, the Copenhagen School of Business, the 2007 ESPE conference, the 2007 Institute for Research on Poverty conference at Wisconsin-Madison and the 2007 EALE conference.
} 


\section{Introduction}

This paper investigates the relation between pre-school care and child outcomes. Specifically, we consider effects on child outcomes of enrolment in universal publicly subsidized high quality center based child care and family day care for three-year-olds in Denmark vis-à-vis parental care. Center based care, or pre-school, is the most common type of care for this age group: 63\% of all threeyear-olds were enrolled in this type of care in 1999. Furthermore, we investigate the effects of hours - the treatment intensity - given selection into a specific type of non-parental care.

Because of the high usage of child care, which is not limited to a Scandinavian setting, allowing parents (or, more precisely, mothers) to participate in the labor market, a natural question to ask is how children are affected by this choice. Child care may be viewed as simply 'taking care' of children, yet an alternative view is that child care is, in effect, a type of early childhood investment in the development of social and academic skills. Depending on the content of the care program, one may easily imagine a variety of effects from enrollment, which may also vary across children. This study focuses on the development of non-cognitive skills such as measures of emotional symptoms, conduct problems, hyperactivity/inattention problems, peer relationship problems, and pro-social behavior. As our outcome variable we use the strength and difficulties questionnaire index (SDQ); a standard behavioral measure in the child development literature, see e.g. Goodman (1997). We measure outcomes at age seven.

There exists a large literature on child development and non-parental care, especially on care for disadvantaged children. See Blau and Currie (2006), Currie (2001), and Ruhm (2004) for excellent surveys. Yet as pointed out by Currie (2001), the literature is rather silent about the effects of regimes with universal pre-school and family day care programs such as the Danish or Canadian one. ${ }^{1}$ This is despite both public and academic interest, see Currie (2001). Firstly, because these programs are not limited to include disadvantaged children, but are offered to the entire population, our results will inform about the effects of modes of care for children across a range of different socio-economic backgrounds. Secondly, exactly because the group of children in for example preschool is not homogenous, the effects may not be the same had pre-school been offered to

\footnotetext{
${ }^{1}$ Universal pre-school is also offered in certain states within the US. Examples are Georgia (since 1995), New York (1997), and Oklahoma (1998). California provides a program targeted at low-income children. See Blau and Currie (forthcoming).
} 
disadvantaged children only. See e.g. Ammermüller and Pischke (2006) on peer-effects in primary schools. In other words, it may be hard to extrapolate from the findings from the literature on disadvantaged children to a regime with universal care programs, even for the group of children with adverse family backgrounds.

Another important contribution of our paper is the evaluation of effects of hours in non-parental care. Some studies focus solely on the effects of maternal employment patterns and consider hours (or extent) of work, see for example Bernal and Keane (2006), Gregg, Washbrook, Propper, and Burgess (2005), Parcel and Menaghan (1994), and Ruhm (2004), while Blau (1999) investigates the effects of child care characteristics on child outcomes and include a measure of hours in care. Common to these analyses is that they investigate the effect of hours for the pooled sample of children. Whether the studies include hours in a linear fashion or a set of dummies, part of the identifying variation will in this way stem from observations that are 'far apart' in terms of hours. The estimates must subsequently be interpreted as the effect of differences in hours including all indirect effects stemming from parents' different (labor market) behavior. Instead, we adopt a strategy similar to Behrman, Cheng, and Todd (2004); we consider the marginal effects on outcome incurred by increasing hours in a given type of non-parental care by a small amount. Performing local comparisons greatly decreases the likelihood of indirect effects and allows us to interpret the resulting estimates as direct effects of changes in hours. Furthermore, the estimator allows for selection into non-parental care to be based on unobservables, but conditional on choosing nonparental care, the choice between hours must be based on observables only. The cost is, of course, that we can only speak about the effects of smaller changes in hours relative to a given baseline.

Estimations are carried out using a longitudinal survey following children born in 1995. The survey holds information about children, mothers, and fathers and is linked to highly reliable administrative registers providing us with crucial background information about the parents and their labor market behavior. We use this rich mine of information to estimate our parameters of interest, using OLS. Furthermore, we have access to plausible exogenous variation in the take-up of pre-school via a pseudo-experiment generating waiting lists for pre-school in some municipalities while guaranteeing open slots in others. See Simonsen (2006) for an evaluation of similar variation in mother's employment following child birth. Presumably because of the difficulties in finding valid exogenous variation in the take-up of child care, only very few studies of the effects of child 
care on child outcomes employ IV estimation, see e.g. Blau and Grossberg (1992), James-Burdumy (2005), and Bernal and Keane (2006). Furthermore, according to the latter, the instruments used in the two former studies are extremely weak.

Our results indicate that being enrolled in non-parental care at age three is neutral compared to home care. However, if one acknowledges that non-parental care is not a well-defined counterfactual, it becomes clear that the first result is not very informative. ${ }^{2}$ We find that being enrolled in pre-school does not lead to significant differences in non-cognitive child outcomes no matter the gender or mother's level of education. Family day care, on the other hand, seems to significantly deteriorate outcomes for boys whose mothers have a lower level of education. This last set of results is confirmed using the above pseudo-experiment as an instrument. Finally, increasing hours in family day care from 30-40 hours per week to 40-50 hours per week and hours in preschool from 20-30 hours per week to 30-40 hours per week leads to significantly poorer child outcomes.

The remainder of the paper is organized as follows: Section 2 provides a description of the data and the institutional set-up, Section 3 discusses child outcomes as well as the linkages between child care enrollment and child outcomes. Section 4 presents our empirical strategy, Section 5 the regression results and Section 6 the IV analysis. Finally, Section 7 concludes.

\section{Data and Institutional Framework}

We exploit a unique panel dataset on children's outcomes, modes of care, and parental background information, known as the Danish Longitudinal Survey of Children (DALSC). The data consists of repeated surveys of the primary parent (typically the mother) of about 6,000 children born between 15 September and 31 October 1995. The first survey took place when the children were 6 months old, the second when they were around $3 \frac{1}{2}$, and the third at age $7 \frac{1}{2}$ when the children had all started first grade (age 7 in Denmark). Thus, 3 waves of this data are currently available: 1996, 1999 and 2003. ${ }^{3}$ The fathers of these children were surveyed separately in some of these waves. In addition, a

\footnotetext{
${ }^{2}$ See also a recent paper by Bernal and Keane (2006) who find significant differences in the effects of child care depending on the type of care.

${ }^{3} \mathrm{~A}$ fourth wave is being fielded in 2007.
} 
special segment on children's health and welfare was added to the mother survey in 2003. This panel survey data has been merged to precise information on parents' educational attainment, labor market status, hours of work, wages and income in the period 1994-2002, extracted from Danish administrative registers. Child care enrolment status is measured in 1999 and child outcomes in 2003. Figure 1 below shows the timing of our set-up. In what follows, we will consider exposure to child care at age three and the subsequent child outcomes measured at age seven.

\section{FIGURE 1}

TIMING OF SET-UP

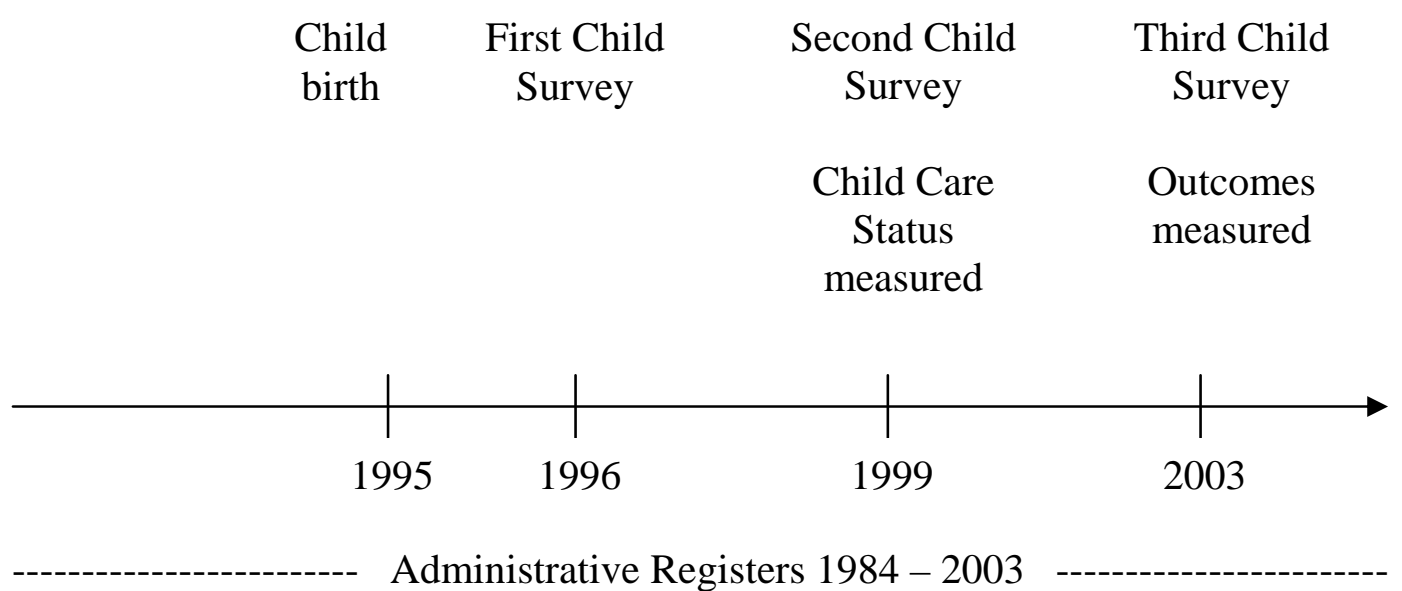

\subsection{The Organization of Day Care and Pre-school Programs in Denmark}

Day care and pre-school programs in Denmark (along with other Nordic countries) are characterized by both high quality expenditure levels per capita compared to other countries and usage, see Datta Gupta, Smith and Verner (forthcoming) for an overview of the impacts of generous family-friendly schemes including publicly provided daycare available in Nordic countries. Requirements of qualifications of child care staff are extensive compared to other EU (and OECD) countries and the number of children per staff is much lower, see OECD's Family Database. In Danish pre-schools, the average staff:child ratio is 1:7, whereas in the US and Canada, for example, the corresponding ratio is 1:12 (1:14 for teaching staff), in Spain 1:13, and France 1:19. In fact, 
according to OECD’s Family Database, Denmark has the lowest average number of children per staff in pre-schools among all OECD countries. Danish child care is for the major part publicly provided and organized within the 271 municipalities, ${ }^{4}$ which are typically smaller units with on average 50,000 inhabitants. Here we focus on care for three-year-olds.

In 1999 (when the children in our sample were three years old), the average yearly expenditures for a slot in center-based pre-school for three-year-olds were approximately $\$ 8,000$. This is significantly higher than the expenditures for, for example, the American Head Start Program aimed at low-income families, which costs around \$5,000 per year, see Currie (2001), and roughly the same as the expenditures for the universal Canadian child care program, see Baker et al. (2005). Family day care (see below for description) is more expensive than center-based pre-school; the average yearly price is about $\$ 10,000 .^{5}$ This is presumably because staff:child ratios are higher (minimum of 1:5) for this type of care for the age group in question.

The regulations of municipality provided child care institutions are described in the Law of Service (Serviceloven). The Law of Service offers general guidelines as to the content of municipality provided care, yet the specific details are decided by the institutions. Overall, institutions must supply care, education, and opportunities to play, all in co-operation with parents. The educational content of municipality provided care involves development of personal, linguistic, and physical skills. Furthermore, children must develop their understanding of nature and culture.

Parents apply for child care by sending an application to the municipality; the child care institutions are not involved in the allocation process. All children are eligible for municipality child care, including children born to unemployed parents. ${ }^{6}$ It is in fact illegal to exclude certain groups of children from participating. This means that children's right to child care enrolment is not affected by their parents' transitions in and out of the labor market. Presumably, if child care does contribute to the development of social and academic skills, we may expect such disruptions to be detrimental to learning.

\footnotetext{
${ }^{4}$ Bornholm is excluded from the analysis because it underwent a municipality reform during the period.

${ }^{5}$ For $0-2$ year olds, family day care is the cheaper option.

${ }^{6}$ The only exception occurs if one of the parents takes formal publicly supported maternity or child care leave aimed at the child in question. Siblings can still be placed in child care during formal leave, though.
} 
Municipalities provide both pre-schools (that may be integrated with nursery centers for 0-2 year olds) and family day care for children within the relevant age group, and the local government is free to decide on the distribution of these two types of care within the municipality. Similarly, opening hours may vary across municipalities but must 'cover local needs'. In general, opening hours in pre-school during week days are between 6.30 am and $5.00 \mathrm{pm}$. Family day care, on the other hand, is more flexible in terms of hours, which can be arranged on an individual basis. In case of waiting lists, open slots in child care are allocated according to length of time on the waiting list and age. Only if a child is disabled, is an immigrant, or if the child has older siblings enrolled in municipality provided care can a child jump the waiting list.

The average pre-school facilitates about 60 children, who are split into smaller groups of about 20, and employs around 9 permanent teachers plus a number of assistants and other staff, thus allowing for considerable specialization of labor. Pre-school teachers in permanent positions must have a degree in teaching (medium length further education or 15-16 years of education) and specialize in young children. Pre-schools may be owned by the municipality. No matter the owner status, the municipalities are required by law to monitor the institutions closely regarding educational content as well as safety and hygiene. Evaluation of the former requires ensuring that the personnel have the necessary qualifications, whereas evaluation of the latter includes accident-preventing measures, play-grounds, transport, sleeping facilities, toys, hygiene, and insurance schemes.

In contrast, family day care takes place in private homes, and the carers are directly employed by the municipality. Again, the municipalities must approve the facilities and the qualifications of the carer. There may be up to five children in each home, and in some municipalities the carer's own children under the age of three enter into the total number of children in the family day care. The carer will then receive compensation from the municipality for taking care of her own children. Family day carers are not required to have a degree in teaching but are offered shorter (3-week) vocational courses.

Table 1 compares the educational level and the gender distribution of staff in pre-schools and family day care. Staff in pre-schools also includes assistants, managers, cleaning and kitchen personnel etc., whereas staff in family day care only consists of the carer herself. From this table, it is clear that children enrolled in pre-schools are met with higher qualified staff, even when non- 
teaching staff is included; staff in pre-schools is much more likely to have a degree in teaching compared to family day carers. Furthermore, there are nine times as many men employed in preschools as in family day care.

TABLE 1

CHARACTERISTICS OF STAFF IN

FAMILY DAY CARE AND PRE-SCHOOLS

\begin{tabular}{lcc}
\hline \hline & $\begin{array}{c}\text { Family Day Care } \\
\text { Mean }\end{array}$ & $\begin{array}{c}\text { Pre-school } \\
\text { Mean }\end{array}$ \\
\hline High school or below & 0.38 & 0.29 \\
Vocational degree & 0.54 & 0.16 \\
in paedagogics & 0.00 & 0.01 \\
Medium length further education & 0.07 & 0.53 \\
in paedagogics & 0.02 & 0.50 \\
Long further education & 0.01 & 0.01 \\
in paedagogics & 0.00 & 0.00 \\
Male & 0.01 & 0.09 \\
\hline
\end{tabular}

Source: $10 \%$ representative sample of the Danish population

Prices are set at the municipality level once a year and hold throughout the municipality for a given type of care. Parents pay a maximum of 33\% of the total costs of providing care, and the price is reduced with lower income and number of siblings enrolled in public care. The subsidy scheme is the same for both pre-school and family day care. The maximum number of children per pre-school teacher is determined through collective bargaining between the municipalities and the pre-school teachers' trade union (BUPL). The norm for 1999 was set at the 1997 collective bargaining. These institutional details will turn out to be important for our identification strategy described below.

\section{Child Outcomes and Non-Parental Care}

There exist two strands of the literature on child outcomes - cognitive as well as non-cognitive- and non-parental care within the field of economics. One focuses largely on the effects of maternal employment in general and less on the alternative modes of care, ${ }^{7}$ whereas another branch considers the effects of pre-school interventions for disadvantaged children.

\footnotetext{
${ }^{7}$ An important exception is Bernal and Keane (2006), who distinguish between formal care (center-based care and preschool) and informal care. Relatedly, Gordon, Kaestner, and Korenman (2007) investigate health outcomes and finds that greater time spent in center-based care is associated with adverse outcomes as measured by respiratory problems and ear infections.
} 
Overall, there is limited consensus in the literature about the effects of child care and maternal employment. Some studies suggest that maternal care during childhood is essential for child development, often measured by the Peabody Picture Vocabulary Test (e.g. Parcel and Menaghan (1994)). A recent study, for example, by Baker, Gruber, and Milligan (2005) considers a large scale change in the child care system in Quebec, Canada. The policy change implied that all five-yearolds have access to full-time pre-school and that the out-of-pocket price for child care cannot exceed \$5 per day. Exploiting the before-after Quebec-versus-other regions variation, the authors find that the effects on child (and parent) outcomes of the transition to a regime with universal highly-subsidized child care are clearly negative. Other studies find negative or mixed effects (Gregg, Washbrook, Propper, and Burgess (2005), Stafford (1987), Waldfogel, Han, and BrooksGunn (2002)) of maternal care. Bernal and Keane (2006), using the NLSY, distinguish between different types of care; they investigate the effect on cognitive ability of participating in formal care (center-based care and pre-school) and informal care, both compared to home care, for children of single mothers. Their findings suggest that this group of children benefit from being enrolled in the former but experience adverse outcomes when participating in the latter, less expensive, option. One reason for the lack of consensus in the literature may stem from variation in the quality of nonparental care; high quality care may, for example, neutralize potentially negative effects of maternal employment, see also Gregg et al. (2005).

For disadvantaged children, however, the literature suggests that participation in (expensive) programs aimed directly at this group is beneficial to participating children, in fact considerably more so than giving families of these children unrestricted cash transfers (Currie, 1994). One example of a successful intervention is the Head Start Program, see e.g. Currie (2001), Currie and Thomas (1995, 1999), and Currie, Garces, and Thomas (2002). Others are the Perry Preschool Project, the Abecedarian Program, and the Chicago Child-Parent Centers; see Currie and Blau (forthcoming) and Heckman and Masterov (2007).

The view that disadvantaged children benefit from high quality care is also put forward in Knudsen et al. (2006). This paper is a joint venture by an economist, a neurologist, a psychiatrist, and a sociologist. Among the conclusions from this paper is that interventions aimed at improving the situation for disadvantaged individuals should start as early as possible when the brain is more 
plastic. This is especially important because early learning is crucial for later learning (see Knudsen et al. (2006), p. 3):

"Both the mastery of skills that are essential for economic success and the development of their underlying neural pathways follow hierarchical rules in a bottom-up sequence such that later attainments build on foundations that are laid down earlier”.

From the literature, therefore, we can infer that for evaluations of the effects of maternal care 1) the counter-factual state matters as does 2) the group under investigation. As described above, here we focus on a large-scale, high quality but expensive, publicly funded universal child care program for three-year-olds; a much under-researched area, see Currie (2001).

One issue is how modes of care affect child outcomes; another is the effects of the intensity of a given treatment. Specifically, one may be interested in assessing how the effect of placing a child in pre-school for 20 hours differs from that of 45 hours. These two scenarios may lead to very different outcomes; one allows for substantial time with both parents in addition to time with peers, whereas the other to a higher degree restricts time with parents. Studies (e.g. Blau (1999), Gregg et al., Ruhm (2004)) typically find that the more hours are spent away from the parents, the worse are child outcomes.

A separate question is how to choose relevant measures of child outcomes. Previously, the literature has focused more on cognitive outcomes (measures of IQ), yet Currie (2001) suggests that though they are important predictors of future economic outcomes, such measures are often flawed and point to the use of measures of school readiness instead or in addition. Pre-school teachers, for example, emphasize the importance of non-cognitive skills as prerequisites for learning. The same point is made by Knudsen et al. (2006). ${ }^{8}$ Furthermore, non-cognitive skills are found to be as important for school enrollment decisions as cognitive skills (see Heckman, Stixrud and Urzua (forthcoming)), and Heckman and Cunha (2006) find that non-cognitive skills promote the formation of cognitive skills but not vice versa. Similarly, Currie and Stabile (forthcoming) find that mental health conditions as measured by Attention Deficit Hyperactivity Disorder (ADHD) affect future test scores and schooling attainment negatively, and Segal (2006) demonstrates that eight

\footnotetext{
${ }^{8}$ Knudsen et al. (2006), p. 4: “Cognitive, linguistic, social, and emotional competencies are interdependent, all are shaped powerfully by the experiences of the developing child, and all contribute to success in the workplace".
} 
grade behavior is as important for earnings as eight grade test scores. Finally, Segal (forthcoming) finds that student behavior, at least during adolescence, is persistent.

As our outcome of interest we have available a measure of non-cognitive skills based on the so called Strength and Difficulties Questionnaire (SDQ); a standard behavioral measure in the child development literature, see Goodman (1997) for a description of this measure and Andersen, Deding, and Lausten (2006) for a Danish application. In our case, the questionnaire is filled out by the primary parent (most often the mother) of the child when the child is seven years old. Importantly, this means that our outcome is measured at a different (future) point in time than our treatment. Had this not been the case, or had the two types of information somehow been linked in the survey, one may have feared that mothers would be inclined to rationalize their choice of child care and overestimate good child behavior, which could bias our results below. Clearly, even if mothers' responses are biased, as long as this is unrelated to choice of mode of care, it will not cause problems for our identification strategy. Furthermore, all children have started school at age seven, and parents' reference points when evaluating child behavior are therefore the other children in school. Importantly, their (current) reference points do not depend on whether the child has been taken care of at home, in family day care, or in pre-school.

The SDQ index is based on emotional symptoms, conduct problems, hyperactivity/inattention problems, and peer relationship problems. See Appendix A, Table A1 for a list of the questions used to construct the $S D Q$ index and www.sdqinfo.com for further details. The measure takes on discrete values in the interval between $0-40$, where 0 indicates no behavioral problems. Research suggests that the SDQ and Rutter questionnaires correlate highly and do equally well in terms of classifying behavior, see Goodman (1997). Also, the SDQ questionnaire offers additional advantages such as coverage of inattention, peer relationships, and pro-social behavior. Figure 2 below shows the distribution of the $S D Q$ index in our sample. 
FIGURE 2

DISTRIBUTION OF SDQ INDEX

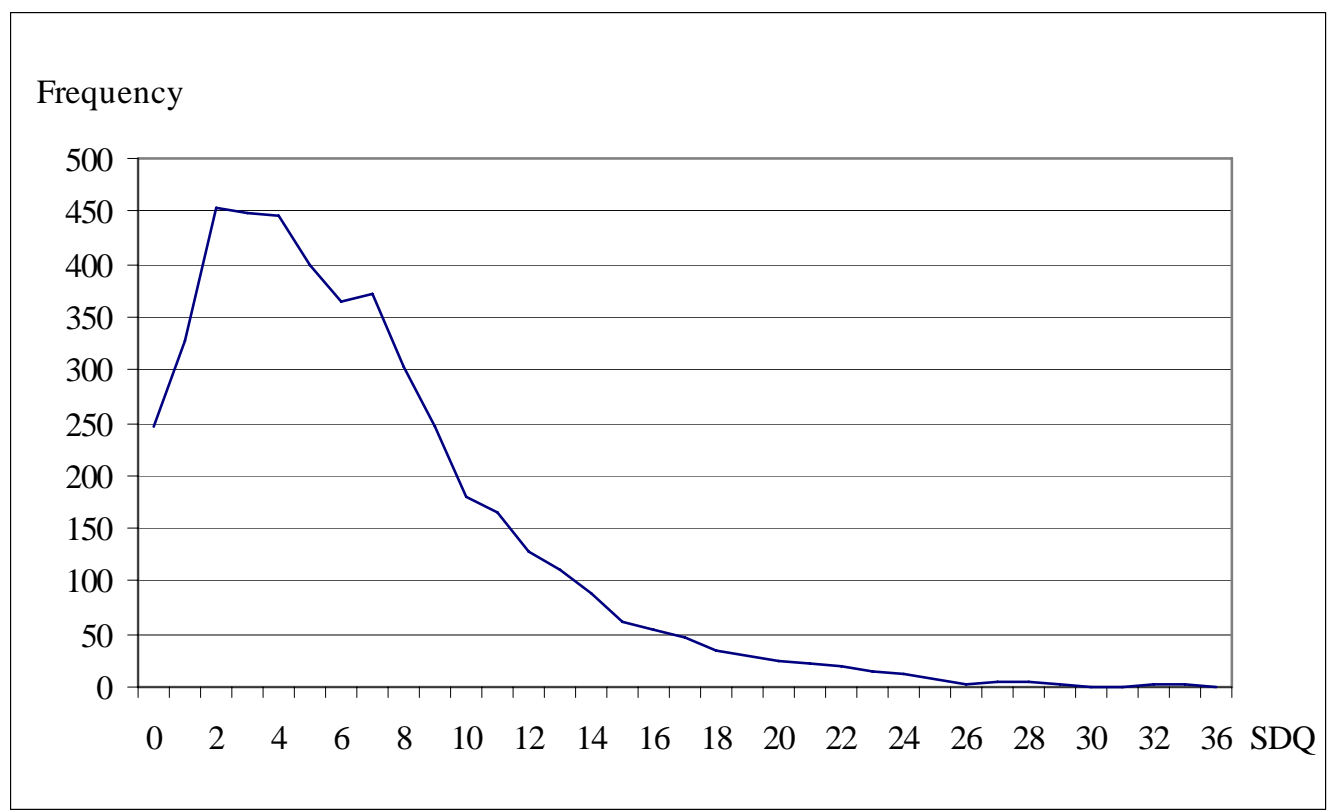

Source: Data used for estimation purposes. SDQ below 14 is 'normal', between 14-16 is 'borderline', and above 16 is 'abnormal'. Danish mean for $7 \frac{1}{2}$ year olds 6.55, US mean for 4-7 year olds 7.4, UK mean for 5-10 year olds 8.6. See www.sqdinfo.com.

TABLE 2

TAKE-UP OF CARE 3-YEAR OLDS AND SDQ INDEX AT AGE $7^{\mathrm{a}}$

\begin{tabular}{lcc}
\hline \hline & Share & $\begin{array}{c}\text { Mean SDQ } \\
\text { index }\end{array}$ \\
\hline Home care & 0.15 & 6.48 \\
& & $(5.29)$ \\
Municipality family day care & 0.16 & 6.80 \\
& & $(5.15)$ \\
Municipality pre-school & 0.66 & 6.52 \\
& & $(5.04)$ \\
Private care & 0.03 & 5.83 \\
& & $(3.93)$ \\
Other types of care & 0.01 & 7.15 \\
& & $(5.68)$ \\
\hline
\end{tabular}

Mean hours in non-parental care

30.88 (10.96)

${ }^{\mathrm{a}}$ Source: Own calculations, data used for estimation purposes 
Table 2 above shows the take-up of different modes of care, parental and otherwise, and mean SDQ index (measured at age 7) along with mean hours in non-parental care. ${ }^{9}$ We see that around a seventh of the children are taken care of at home and that municipality-run pre-school centers constitute the most common type of non-parental care. Participation in center-based care is high in an international comparison; according to Currie (2001), in 1995 around 31\% of American threeyear-olds received such care. On the outset, there is little variation in child outcomes across types of care, and children spend on average 30 hours per week in non-parental care.

\section{Parameters of Interest}

This section first discusses potential parameters of interest and then considers identification of these parameters. In this paper, one goal of the evaluation is to measure the effect or impact of mode of care on our outcome variable, the strengths and difficulties index, $S D Q$, relative to some other type of care. More precisely, we consider the effects on child outcomes at age seven of participating at age three in some form of publicly provided child care compared to home care. That is, we ignore the small fraction of children participating in private and other specialized care. We also only include children whose mother filled in the questionnaire. ${ }^{10} \mathrm{~A}$ second goal of the paper is to evaluate the effects of the intensity of treatment. Put differently, does it matter whether a child is placed in non-parental care for 30 hours compared to 20 hours conditional on choosing some type of publicly provided care such as pre-school?

Consider first participation in a municipality provided child care program, $M P$, relative to home care. Let $M P=1$ indicate participation in such a program, whereas $M P=0$ indicates home care. Let $S D Q_{0}$ be potential outcome in home care and $S D Q_{1}$ the potential outcome in municipality provided care. We are now faced with the fundamental problem that we do not observe the same child both in home care and municipality provided care at the same point in time. In this paper, we consider the average effect of municipality provided care for the group of participants:

\footnotetext{
${ }^{9} \mathrm{SDQ}$ is missing for 15 percent of the sample. Running mode specific probits, we conclude that the reporting problem is statistically unrelated (at the $5 \%$ significance level) to any observable characteristics in our conditioning set, see Table 3 for the list of variables.

${ }^{10}$ This is the case for $99 \%$ of the children in the survey.
} 


$$
E\left[S D Q_{1}-S D Q_{0} \mid M P=1\right]
$$

Other parameters, for example focusing on the probability of abnormal child outcomes, may be of interest as well. The reason for estimating average effects is twofold: firstly, municipality provided care - our treatment - is designed to cover the needs of an average child and not so much children with abnormal behavior and needs. In fact, children with extreme problems are likely to be sent to special institutions and are fairly rare in our sample; $91 \%$ of children are classified as normal, see definition in Section 2. Therefore, we do not expect much action with regard to child care participation for borderline and abnormal groups. Secondly, (1) should be an extremely important input into the decision rule for parents of 'average' children. This group of parents is not necessarily afraid that their child will turn out to have extreme behavior, but may still - because there exists gradations of normal - care about whether sending their child off to be taken care of outside of the home will move child development in one or the other direction.

There is an obvious problem with the parameter defined in (1), however. In particular, (1) will be some weighted average of the effects of being enrolled in pre-school and family day care. Thus, estimating the average effect of being enrolled in some type of municipality provided care does not result in an easily interpretable parameter, but does, nonetheless, correspond to the parameters being estimated in much of the literature.

We therefore continue to investigate whether participation in different types of municipality provided child programs results in different outcomes compared to home care. In order to do this, we need to extend our framework slightly. Let $S D Q_{j}$ be the potential outcome, $j=0,1,2$ :

$$
j=\left\{\begin{array}{l}
0 \text { if home care } \\
1 \text { if family day care } \\
2 \text { if pre-school }
\end{array}\right.
$$

We consider the following parameters:

$$
E\left[S D Q_{1}-S D Q_{0} \mid F C=1\right]
$$


where FC indicates family day care participation. Thus, (2) is the average effect of participating in family day care compared to home care for the group of children enrolled in family day care. Furthermore, we consider

$$
E\left[S D Q_{2}-S D Q_{0} \mid P S=1\right],
$$

where PS indicates pre-school participation. (3) is then the effect of participating in pre-school compared to home care for the group of children enrolled in pre-school.

All three parameters, (1) - (3), discussed above should be interpreted as the effects of a given type of care compared to the alternative home care, including any effects arising via parents' different labor market behavior and income in the two states in the year of treatment. In principle, we would like to adjust for these variables in the year where treatment is taking place to isolate the effect of mode of child care. Yet, exactly because such variables are affected by the treatment, this is not possible; see Rosenbaum (1984). This problem is common to all observational studies attempting to evaluate the effects of child care.

Finally, we consider the effects of participating in pre-school compared to family day care for the group of children enrolled in pre-school:

$$
E\left[S D Q_{2}-S D Q_{1} \mid P S=1\right]
$$

In considering this latter parameter, we avoid having to deal with the potential non-random selection out of non-parental care.

The parameters presented in (1) - (4) are all concerned with comparing different types of care. As pointed out, another interesting question is whether the intensity of care matters. We follow Behrman, Cheng, and Todd and explore the following parameters:

$$
E\left[S D Q_{1}(t+\Delta t)-S D Q_{1}(t) \mid F C=1, t\right]
$$


and

$$
E\left[S D Q_{2}(t+\Delta t)-S D Q_{2}(t) \mid P S=1, t\right] .
$$

(5) and (6) are the average effects of increasing time in a given type of publicly provided care from $t$ to $t+\Delta t$ conditional on selecting municipality provided family day care or pre-school and spending $t$ hours in this type of care, respectively. Focusing on decisions on the intensive margin allows us to ignore the selection into a specific type of non-parental care. We only consider the marginal and not the cumulative effects of hours; the reason is that while it may be valid to compare children who spend 40 hours in non-parental care with those spending 30 hours (i.e. to perform local comparisons), comparing children spending 40 hours in non-parental care with those spending 10 hours potentially introduces large indirect effects, particularly from the mother's income and labor market status. As above, it is not possible to condition on these variables because they are affected by the choice of child care. The latter set of estimates will therefore be harder to interpret and presumably further away from the direct effects. The cost of our approach is clearly that we can only address effects stemming from local variations in the choice of hours. 
TABLE 3

DETAILED DESCRIPTION OF VARIABLES

\begin{tabular}{|c|c|c|}
\hline Variable & Description & Source \\
\hline \multicolumn{3}{|l|}{ Child Care at age three: } \\
\hline Home care, $H$ & $\begin{array}{l}\text { Dummy for being taken care of by parents or } \\
\text { grandparents at home }\end{array}$ & $\begin{array}{l}\text { Danish Longitudinal } \\
\text { Survey of Children }\end{array}$ \\
\hline Municipality family day care, FC & $\begin{array}{l}\text { Dummy for being enrolled in municipality } \\
\text { provided family day care in } 1999 \text { (at age three) }\end{array}$ & $\begin{array}{l}\text { Danish Longitudinal } \\
\text { Survey of Children }\end{array}$ \\
\hline Municipality pre-school, PS & $\begin{array}{l}\text { Dummy for being enrolled in municipality } \\
\text { provided pre-school care in } 1999 \text { (at age three) }\end{array}$ & $\begin{array}{l}\text { Danish Longitudinal } \\
\text { Survey of Children }\end{array}$ \\
\hline Municipality provided program, $M P$ & $\begin{array}{l}\text { Dummy for being enrolled in either municipality } \\
\text { provided family day care or pre-school in } 1999\end{array}$ & $\begin{array}{l}\text { Danish Longitudinal } \\
\text { Survey of Children }\end{array}$ \\
\hline Private care & $\begin{array}{l}\text { Dummy for being enrolled in privately } \\
\text { provided care in } 1999 \text { (at age three) }\end{array}$ & $\begin{array}{l}\text { Danish Longitudinal } \\
\text { Survey of Children }\end{array}$ \\
\hline Other care & $\begin{array}{l}\text { Dummy for being enrolled in other types of } \\
\text { care in } 1999 \text { (at age three) }\end{array}$ & $\begin{array}{l}\text { Danish Longitudinal } \\
\text { Survey of Children }\end{array}$ \\
\hline Hours in non-parental care & Number of hours per week in non-parental care & $\begin{array}{l}\text { Danish Longitudinal } \\
\text { Survey of Children }\end{array}$ \\
\hline \# prior non-parental care facilities & $\begin{array}{l}\text { Number of different care facilities a child has been } \\
\text { enrolled in before the current at age three }\end{array}$ & $\begin{array}{l}\text { Danish Longitudinal } \\
\text { Survey of Children }\end{array}$ \\
\hline Pre-school teachers & $\begin{array}{l}\text { Number of pre-school teachers per } 100 \text { children } \\
\text { enrolled (municipality level) }\end{array}$ & Statistics Denmark \\
\hline \multicolumn{3}{|l|}{ Child Characteristics: } \\
\hline Girl & Dummy for being a girl & $\begin{array}{l}\text { Danish Longitudinal } \\
\text { Survey of Children }\end{array}$ \\
\hline Birth month September & $\begin{array}{l}\text { Dummy for being born in September } \\
\text { (all children born in either September or October) }\end{array}$ & Statistics Denmark \\
\hline Siblings & Number of siblings & Statistics Denmark \\
\hline Breast fed & Dummy for being breast fed & $\begin{array}{l}\text { Danish Longitudinal } \\
\text { Survey of Children }\end{array}$ \\
\hline Birth weight (in 1000 grams) & Birth weight in 1000 grams & $\begin{array}{l}\text { Danish Longitudinal } \\
\text { Survey of Children }\end{array}$ \\
\hline \# hospitalizations & Number of hospitalizations before age three & $\begin{array}{l}\text { Danish Longitudinal } \\
\text { Survey of Children }\end{array}$ \\
\hline Physically disabled & Dummy for being physically disabled & $\begin{array}{l}\text { Danish Longitudinal } \\
\text { Survey of Children }\end{array}$ \\
\hline Full term birth & Dummy for full term birth & $\begin{array}{l}\text { Danish Longitudinal } \\
\text { Survey of Children }\end{array}$ \\
\hline Arranged for care & $\begin{array}{l}\text { Dummy for having care arrangements at age } \\
\text { six months }\end{array}$ & $\begin{array}{l}\text { Danish Longitudinal } \\
\text { Survey of Children }\end{array}$ \\
\hline Waiting list & $\begin{array}{l}\text { Dummy for being subject to waiting list for } \\
\text { municipality provided child care at age six months } \\
\text { (may occur even within GAPS municipality) }\end{array}$ & $\begin{array}{l}\text { Danish Longitudinal } \\
\text { Survey of Children }\end{array}$ \\
\hline
\end{tabular}

Table continues on next page 
TABLE 3 CTD

DETAILED DESCRIPTION OF VARIABLES

Mother's Characteristics:

Age

High school or below

Vocational degree

Short further

Medium further

Long further

Labor market experience

Degree of year employed in 1996

Degree of year employed in 1997

Degree of year employed in 1998

Smoker

Single

Non-native speaker

Postpartum depression

Disposable income in 1996

Disposable income in 1997

Disposable income in 1998

Father's Characteristics:

High school or below

Vocational degree

Short further

Long further

Labor market experience

Leave
Mother's age in years

Dummy taking the value one if the mother has

a high school degree or less education

Dummy taking the value one if the mother has a vocational degree

Dummy taking the value one if the mother has a short further education (13-14 years)

Dummy taking the value one if the mother has a medium further education (15-16 years)

Dummy taking the value one if the mother has a long further education (17 years or more)

Mother's labor market experience before giving birth (1995) measured in years

Degree of the employment one year after giving birth

Degree of the employment two years after giving birth

Degree of employment three years after giving birth

Dummy taking the value one if the mother is a smoker

Dummy for being a single mother

Dummy for being a non-native speaker

Dummy for experiencing postpartum depression

Income after tax in 1996

Income after tax in 1997

Income after tax in 1998

Dummy taking the value one if the father has a high school degree or less education

Dummy taking the value one if the father has a vocational degree

Dummy taking the value one if the father has

a short further education

Dummy taking the value one if the father has

a long further education

Father's labor market experience before giving

birth (1995) measured in years

Whether father took leave in connection with child birth
Statistics Denmark

Statistics Denmark

Statistics Denmark

Statistics Denmark

Statistics Denmark

Statistics Denmark

Statistics Denmark

Statistics Denmark

Statistics Denmark

Statistics Denmark

Danish Longitudinal Survey of Children Danish Longitudinal Survey of Children

Danish Longitudinal

Survey of Children

Danish Longitudinal

Survey of Children

Statistics Denmark

Statistics Denmark

Statistics Denmark

Statistics Denmark

Statistics Denmark

Statistics Denmark

Statistics Denmark

Statistics Denmark

Danish Longitudinal Survey of Children

Table continues on next page 
TABLE 3 CTD

DETAILED DESCRIPTION OF VARIABLES

\begin{tabular}{|c|c|c|}
\hline \multicolumn{3}{|c|}{ Municipality and Regional Characteristics: } \\
\hline Region 1 & Residing in county of Copenhagen, 1999 & Statistics Denmark \\
\hline Region 2 & $\begin{array}{l}\text { Residing in counties of Frederiksborg } \\
\text { and Roskilde, } 1999\end{array}$ & Statistics Denmark \\
\hline Region 3 & $\begin{array}{l}\text { Residing in counties of Western Sealand } \\
\text { and Storstrøm, } 1999\end{array}$ & Statistics Denmark \\
\hline Region 4 & Residing in county of Fuen, 1999 & Statistics Denmark \\
\hline Region 5 & $\begin{array}{l}\text { Residing in counties of Southern Jutland } \\
\text { and Ribe, } 1999\end{array}$ & Statistics Denmark \\
\hline Region 6 & $\begin{array}{l}\text { Residing in counties of Vejle and } \\
\text { Ringkøbing, } 1999\end{array}$ & Statistics Denmark \\
\hline Region 7 & $\begin{array}{l}\text { Residing in counties of Aarhus and } \\
\text { Viborg, } 1999\end{array}$ & Statistics Denmark \\
\hline Region 8 & $\begin{array}{l}\text { Residing in county of Northern } \\
\text { Jutland, } 1999\end{array}$ & Statistics Denmark \\
\hline Unemployment rate & $\begin{array}{l}\text { Share of unemployed among women in } \\
\text { municipality, 16-49 years of age, } 1999\end{array}$ & Ministry of Interior \\
\hline Single parent children & $\begin{array}{l}\text { Share of single parent children } \\
\text { 0-17 years old in municipality, } 1999\end{array}$ & Ministry of Interior \\
\hline Asylum seekers & $\begin{array}{l}\text { \# of asylum seekers per 10,000 } \\
\text { inhabitants in municipality, } 1999\end{array}$ & Ministry of Interior \\
\hline Third world immigrants & $\begin{array}{l}\text { \# of third world immigrants per 10,000 } \\
\text { inhabitants in municipality, } 1999\end{array}$ & Ministry of Interior \\
\hline Social Democrats & $\begin{array}{l}\text { Largest party in } 1997 \text { municipality election } \\
\text { is social democrats }\end{array}$ & Statistics Denmark \\
\hline Conservatives & $\begin{array}{l}\text { Largest party in } 1997 \text { municipality election } \\
\text { is conservatives }\end{array}$ & Statistics Denmark \\
\hline Liberals & $\begin{array}{l}\text { Largest party in } 1997 \text { municipality election } \\
\text { is liberals }\end{array}$ & Statistics Denmark \\
\hline Child families & $\begin{array}{l}\text { Share of families with children among all } \\
\text { households within municipality }\end{array}$ & Statistics Denmark \\
\hline
\end{tabular}

\section{Regression Results}

In order to determine what type of conditioning set is necessary for our regression estimates of the parameters of interest to be unbiased, we rely on the literature on child development and demand for child care for guidance. In the literature, a child's development is proposed to be a function of current as well as past mode and intensity of care, purchased inputs, and exogenous determinants (production shocks), see Ruhm (2004) for a sketch of such a production function approach. Furthermore, from the literature on demand for child care, e.g. Blau and Hagy (1998), we know that mothers' employment and the costs related to a given type of care are crucial factors. 
Together, these models imply that we need a rich conditioning set describing firstly the types and the quality of available modes of child care. Furthermore, we need information about number of hours in non-parental care. That is, we must have information about the treatment. Here, we use both information from the child panel about type and intensity of the chosen mode of care and municipality specific information from the Ministry of the Interior on quality of child care as measured by for example number of teachers per child, see Currie (2001). To proxy purchased inputs, mothers' employment, and costs related to a given type of care, we include detailed information on income and labor market history - also prior to giving birth - for the parents in our sample, see also Gregg (2005). Presumably, including such information stemming from before the child is born informs about attachment to the labor market but also about ability. In principle, we also need information about past choices of child care. Unfortunately, we do not observe enrolment status before age 3, but we do condition on the parents' labor market behavior during this period. Thus, effectively, we condition on being enrolled in non-parental care: If both parents are full-time employees, the child must be exposed to some form of child care not exercised by the parents. Finally, we need information about the catch-all category of 'production shocks'. Here, we use a variety of information correlated with both child outcome and choice of care. We include information about the child measured at time of birth (birth weight, breast fed, gender, disabilities, number of siblings etc.), parents (geographic location, level of education, smoking behavior, immigrant status, whether the father took leave, whether the mother experienced post-partum depression $^{11}$ ), and municipalities (level of unemployment, number of immigrants, winner of most recent local government election, share of households with children out of all households in municipality). See Table 3 above for a detailed description of the variables and Table A2 in Appendix A for means of the conditioning set across modes of care. ${ }^{12}$

Having discussed our conditioning set, we next present our estimation results. The first column in Table 4 shows selected coefficient estimates from estimating the effect of municipality provided care vs. home. That is, we attempt to uncover (1) above. We see that the parameter estimate to municipality provided program participation is positive, indicating that being enrolled in municipality provided care increases the SDQ index with 0.8 points. Yet, the estimate is not

\footnotetext{
${ }^{11}$ Maternal mental health has been found to be significantly linked to ADHD symptoms in children (e.g. Lesesne et al. (2003)).

${ }^{12}$ In Section 6, we investigate the sensitivity of our results to the exclusion of variables that are potentially endogenous: parental employment after birth but before age three, number of prior care facilities, arranged for care at age six months, on waiting list at age six months. This does not affect our conclusions.
} 
statistically significant at the 5\% level. Remember that a higher value of SDQ index indicates adverse behavior. This result is in line with the findings in Andersen, Deding, and Lausten (2006), who, using the same data set as we do, investigate the effects of parents' labor market behavior on child outcomes.

As pointed out, however, (1) is not easily interpretable, and given the very different structures and contents of the two types of programs, we might expect the effects of the two to differ. To accommodate this, we shift attention to the effect of being enrolled in family day care relative to home care, (2), and the effect of pre-school vis-à-vis home care, (3). Again, we estimate these parameters using OLS in a pooled model. The results are shown in the second column in Table 4. We see that family day care and pre-school are indeed not the same and do not have the same effects on child outcomes. More precisely, being enrolled in pre-school seems neutral compared to home care; the estimated effect is small, 0.4 SDQ points, and insignificant, whereas being enrolled in family day care significantly increases SDQ with 1.8 points. Note that parameter estimates should be seen relative to a mean of 6.6 SDQ points. The average effect of family day care roughly corresponds to the difference in mean SDQ between children born in a family where the mother has some further education and children born in a family where the mother has a high school degree or less education.

Consistent across the two models is that being breast fed, having high birth weight, not being disabled, and being born to a relatively older mother who does not smoke and who is not single is negatively correlated with SDQ. Similarly, children born to fathers with further education have lower SDQ. Put differently, these characteristics are correlated with better child outcomes. 
TABLE 4

SELECTED OLS COEFFICIENT ESTIMATES ${ }^{\mathrm{a}}$

OutCome: SDQ, Municipality PROVIDED PROGRAMS VS. HoME

MEAN SDQ Home: 6.48, MEAN SDQ FAMILY DAy CARE: 6.80, MEAN SDQ PRE-SCHOOL: 6.52

\begin{tabular}{|c|c|c|c|c|}
\hline \multirow[b]{2}{*}{ Variable } & \multicolumn{2}{|c|}{ Model I } & \multicolumn{2}{|c|}{ Model II } \\
\hline & Coefficient & Std. Error & Coefficient & Std. Error \\
\hline \multicolumn{5}{|l|}{ Child care at age 3} \\
\hline Municipality provided program & 0.794 & 0.533 & • & - \\
\hline Family Day Care & $\bullet$ & $\bullet$ & $1.782 *$ & 0.614 \\
\hline Pre-school & $\bullet$ & $\bullet$ & 0.426 & 0.543 \\
\hline \# prior non-parental care facilities & 0.108 & 0.090 & 0.196 & 0.097 \\
\hline Pre-school teachers & -0.025 & 0.054 & -0.038 & 0.054 \\
\hline \multicolumn{5}{|l|}{ Child characteristics } \\
\hline Girl & -0.034 & 0.545 & -0.027 & 0.544 \\
\hline Birth month September & -0.027 & 0.153 & -0.014 & 0.153 \\
\hline Siblings & -0.015 & 0.104 & -0.008 & 0.104 \\
\hline Breast fed & -1.576 & 0.374 & -1.562 & 0.373 \\
\hline Birth weight (in 1000 grams) & -0.374 & 0.127 & -0.372 & 0.127 \\
\hline \# hospitalizations & -0.043 & 0.245 & -0.052 & 0.245 \\
\hline Physically disabled & 1.003 & 0.402 & 0.983 & 0.402 \\
\hline Full term birth & 0.038 & 0.149 & 0.035 & 0.149 \\
\hline Arranged for care & -0.171 & 0.185 & -0.142 & 0.185 \\
\hline Waiting list & 0.191 & 0.208 & 0.214 & 0.208 \\
\hline \multicolumn{5}{|l|}{ Mother's characteristics } \\
\hline Age & -0.115 & 0.024 & -0.118 & 0.024 \\
\hline Vocational degree & -0.240 & 0.615 & -0.254 & 0.615 \\
\hline Short further & -0.423 & 0.770 & -0.447 & 0.769 \\
\hline Long further & 0.135 & 1.779 & -0.022 & 1.779 \\
\hline Labor market experience & -0.022 & 0.017 & -0.020 & 0.017 \\
\hline Degree of year employed in 1996 & 0.282 & 0.340 & 0.302 & 0.340 \\
\hline Degree of year employed in 1997 & -0.271 & 0.355 & -0.292 & 0.355 \\
\hline Degree of year employed in 1998 & -0.313 & 0.305 & -0.328 & 0.304 \\
\hline Smoker & 1.100 & 0.171 & 1.104 & 0.171 \\
\hline Single & 0.840 & 0.480 & 0.848 & 0.480 \\
\hline Non-native speaker & 0.962 & 0.660 & 1.030 & 0.660 \\
\hline Post-partum depression & 1.913 & 0.755 & 1.853 & 0.754 \\
\hline \multicolumn{5}{|l|}{ Father's Characteristics: } \\
\hline Vocational degree & -0.489 & 0.181 & -0.471 & 0.181 \\
\hline Short further & -1.109 & 0.251 & -1.082 & 0.251 \\
\hline Long further & -1.181 & 0.317 & -1.167 & 0.317 \\
\hline Labor market experience & -0.001 & 0.015 & 0.001 & 0.015 \\
\hline Leave & 0.171 & 0.181 & 0.174 & 0.181 \\
\hline \# observations & \multicolumn{2}{|c|}{4343} & \multicolumn{2}{|c|}{4343} \\
\hline $\mathrm{R}^{2}$ & \multicolumn{2}{|c|}{0.105} & \multicolumn{2}{|c|}{0.108} \\
\hline
\end{tabular}

${ }^{\mathrm{a}}$ The full conditioning set is described in Table 3. Cross terms between municipality provided program and mother's level of education and cross terms between municipality provided program and gender are included. Bold coefficients are significant at the $5 \%$ level and italic indicates significance at the $10 \%$ level. * indicates that the family day care coefficient is statistically different from the pre-school coefficient (5\% level). All results robust to clustering at the municipality level. 
As discussed above, a general finding in the literature is that children with poor socio-economic backgrounds benefit from being enrolled in high-quality programs. If treatment effects are heterogeneous, we will not expect the parameters in Table 4 above to be representative for all groups. To address this, we investigate whether the estimated effects differ with mothers' level of education. ${ }^{13}$ Similarly, girls may be affected differently from participation compared to boys. Table 5 shows the effects of family day care and pre-school compared to home care for different subgroups of the population.

\section{TABLE 5}

SELECTED OLS COEFFICIENT ESTIMATES ${ }^{\mathrm{a}}$

OutCOME: SDQ, Municipality PROVIDEd PROGRAMS VS. HOME

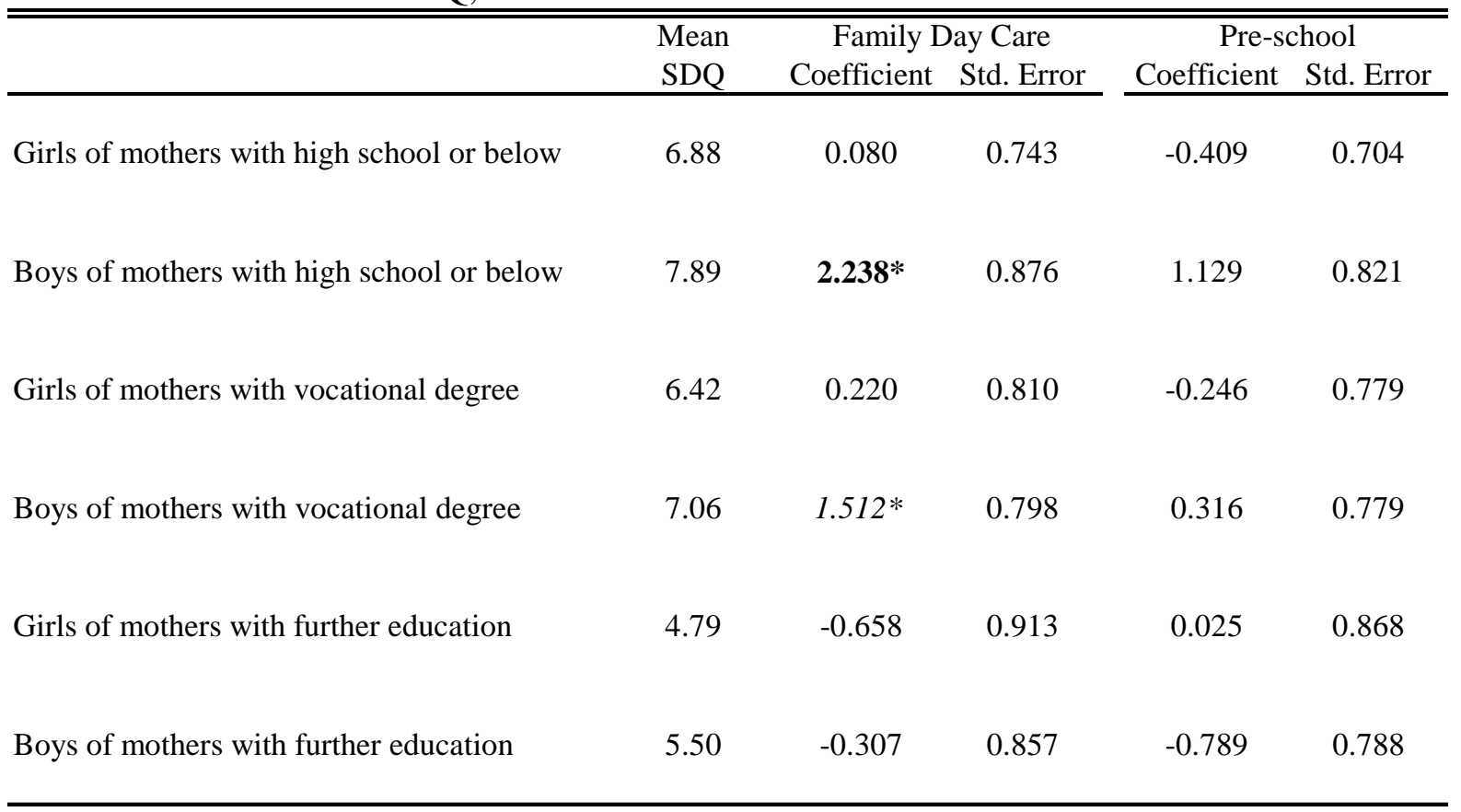

\footnotetext{
${ }^{\mathrm{a}}$ The conditioning set is described in Table 3 . Bold coefficients are significant at the $5 \%$ level and italic indicates significance at the $10 \%$ level. * indicates that the family day care coefficient is statistically different from the pre-school coefficient (5\% level). Employing an F-test we reject the joint hypothesis that coefficients included in this table are equal. All results robust to clustering at the municipality level.
}

Interestingly, there does seem to be important differences in who is affected by being placed in nonparental care. The result that pre-school works as well as parental care holds true across all subpopulations considered, though some point estimates are relatively large but insignificant. However, the result that family day care causes child outcomes to deteriorate is clearly only significant in the case for boys, and then only when the mother has relatively low education (high

\footnotetext{
${ }^{13}$ Mothers' and fathers' level of education correlate highly. Thus, we focus on mother's level of education only.
} 
school or below, or vocational degrees). Boys born to mothers with a high school degree or below will observe an increase in SDQ of 2.2 points compared to being taken care of at home. Similarly, boys born to mothers with a vocational degree experience a 1.5 point increase in SDQ, though this result is only significant at the $10 \%$ level.

The literature on the effects of early maternal employment on child outcomes does not agree on whether boys fare better or worse from this compared to girls; see Ruhm (2004). Presumably, part of the explanation is the lack of information about the type and quality of non-parental care. However, Jacobs (2002) finds that girls do have a lower incidence of behavioral problems in general, and Goldin, Katz, and Kuziemko (2006) document that girls have a much lower probability of participating in special education programs. Thus, boys are, on the outset, more vulnerable and therefore maybe more sensitive to their environment. ${ }^{14}$

Also, as demonstrated above, there are important differences between family day care and preschool. Specifically, only one (pre-school) allows for male supervision. For obvious reasons, there exists very little evidence on the effect of teacher gender on child outcomes. According to Whitebook (1999), 98\% of all American child care staff is female. A study by Dee (2006) on the effects of teacher gender on $8^{\text {th }}$ grade children's test score performance based on the NELS 88 finds that girls improve their outcomes when taught by women and boys when taught by men, controlling for student, teacher and classroom characteristics. Whether the same would apply to children of other ages is not clear. From the literature on paternal absence and child behavior, however, there does seem to be some evidence that boys suffer more from an absent father than do girls, see e.g. Camara and Resnick (1988) and Mott, Kowaleski-Jones, and Menaghan (1997). Thus, male supervision and role models seem more important for younger boys, and the result may contribute to explaining why boys benefit more from pre-school than girls.

Another interesting question is whether parents should choose pre-school over family day care, given that the child is not in parental care. If in fact the parametric linear model is correct and our conditional independence assumption holds true, we could easily answer this question and uncover (4) by comparing the two treatments in Table 5 above. Alternatively, one could restrict the sample to include only children in either family day care or pre-school. If our conditioning set does a poor

\footnotetext{
${ }^{14}$ Boys in our sample have 0.8 points higher SDQ than girls.
} 
job explaining the selection out of home care, we will expect these estimates to differ. The results are shown in Table 6 below. We see that boys born to mothers with lower levels of education would benefit from being enrolled in pre-school compared to family day care. The results are not different from what one finds from Table 5. Thus so far, there does not seem to be evidence that our conditional independence assumption is violated.

\section{TABLE 6}

SELECTED OLS COEFFICIENT ESTIMATES ${ }^{\mathrm{a}}$

OUTCOME: SDQ, MUNICIPALITY PROVIDED PRE-SCHOOL VS. FAMILY DAY CARE

\begin{tabular}{|c|c|c|c|}
\hline & \multirow{2}{*}{$\begin{array}{c}\text { Mean } \\
\text { SDQ }\end{array}$} & \multicolumn{2}{|c|}{ Pre-school } \\
\hline & & Coefficient & Std. Error \\
\hline Girls of mothers with high school or below & 6.85 & -0.400 & 0.549 \\
\hline Boys of mothers with high school or below & 8.00 & -1.071 & 0.632 \\
\hline Girls of mothers with vocational degree & 6.40 & -0.391 & 0.491 \\
\hline Boys of mothers with vocational degree & 7.12 & -1.254 & 0.537 \\
\hline Girls of mothers with further education & 4.81 & 0.785 & 0.570 \\
\hline Boys of mothers with further education & 5.53 & -0.404 & 0.515 \\
\hline
\end{tabular}

${ }^{\mathrm{a}}$ The conditioning set is described in Table 3 . Bold coefficients are significant at the $5 \%$ level and italic indicates significance at the $10 \%$ level. All results robust to clustering at the municipality level.

Finally, we consider the effects of hours per week in family day care (5) and pre-school (6) conditional on choosing a specific type of municipality provided care. We split hours in care into six categories: 10 hours or less, 10-20 hours, 20-30 hours, 30-40 hours, 40-50 hours, and above 50 hours. Unfortunately, because we are performing comparisons at the margin (comparing, for example, the group of children spending 20-30 hours in family day care with those spending 30-40 hours), the size of our data set does not allow us to construct estimates specific to gender and mother's level of schooling while maintaining power. Table 7 below shows these results. We see that increases in hours from $0-10$ to $10-20$ and 10-20 to 20-30 are benign, no matter the choice of care. This is maybe not surprising since spending less than 30 hours in non-parental care allows for 
significant time both with the parents and with peers. Further increasing hours, however, seems to significantly worsen child outcomes.

TABLE 7

EFFECTS OF HOURS IN CARE

OUTCOME: SDQ, MUNICIPALITY PROVIDED PROGRAMS

\begin{tabular}{|c|c|c|c|c|c|c|}
\hline & \multirow{2}{*}{$\begin{array}{c}\text { Mean } \\
\text { SDQ }\end{array}$} & \multicolumn{2}{|c|}{ Family Day Care } & \multirow{2}{*}{$\begin{array}{l}\text { Mean } \\
\text { SDQ } \\
\end{array}$} & \multicolumn{2}{|c|}{ Pre-school } \\
\hline & & Coefficient & Std. Error & & Coefficient & Std. Error \\
\hline $10-20$ hours compared to $0-10$ hours & & $\bullet$ & • & 6.55 & 0.253 & 1.951 \\
\hline 20-30 hours compared to 10 -20 hours & 6.45 & -2.980 & 2.024 & 5.77 & -0.523 & 0.587 \\
\hline $30-40$ hours compared to $20-30$ hours & 6.48 & 0.413 & 0.509 & 6.26 & 0.826 & 0.222 \\
\hline $40-50$ hours compared to $30-40$ hours & 6.82 & 0.732 & 0.410 & 6.66 & 0.604 & 0.222 \\
\hline Above 50 hours compared to $40-50$ hours & 7.36 & 3.298 & 4.010 & 7.20 & 0.438 & 1.378 \\
\hline
\end{tabular}

${ }^{\mathrm{a}}$ The conditioning set is the same as that of Table 4 . Bold coefficients are significant at the $5 \%$ level and italic indicates significance at the $10 \%$ level. All results robust to clustering at the municipality level.

\section{Instrumental Variable Results}

An alternative strategy for uncovering our parameters of interest is to look for variation in the takeup of child care which is unrelated to child outcomes. In this section, we exploit that some municipalities provide guaranteed access to pre-school (GAPS). Variation in this policy is used to identify the effect of participating in pre-school compared to family day care, see (4) above. Below, we will argue that the policy fulfills the requirements for being a valid instrument.

The GAPS policy applies to all pre-school children within a municipality; yet the parents cannot themselves decide on a specific pre-school. As mentioned above, in case of waiting lists, open slots in child care are allocated according to length of time on the waiting list and age, and only children with medical needs or older siblings already enrolled in a particular institution along with immigrants may jump the line. It will therefore be extremely important to condition on this 
information in our analysis (see also sensitivity analysis below). Note that waiting lists may occur even in municipalities that do provide GAPS if parents do not accept the offers they are given. Centers may, for example, be placed further away from the home than the parents would prefer. Table 8 shows the distribution of GAPS across the counties of Denmark.

TABLE 8

DISTRIBUTION OF GAPS ACROSS REGIONS

\begin{tabular}{lc}
\hline \hline Counties & $\begin{array}{c}\text { Share of population } \\
\text { facing GAPS }\end{array}$ \\
\hline Copenhagen & 0.701 \\
Frederiksborg and Roskilde & 0.278 \\
W. Sealand and Storstrøm & 0.032 \\
Fuen & 0.056 \\
S. Jutland and Ribe & 0.189 \\
Vejle and Ringkøbing & 0.211 \\
Aarhus and Viborg & 0.418 \\
N. Jutland & 0.437 \\
\hline
\end{tabular}

If parents value pre-school over and above family day care, we should expect GAPS to increase the take-up of pre-school. This can, of course, be tested with our data.

Not only does the instrument have to affect the take-up of pre-school, it also needs to provide us with variation in the take-up of non-parental care, which is (conditionally) unrelated to child outcomes. Two sets of agents can affect whether parents face GAPS: the local government and the parents themselves. Consider first the local government. Clearly, our instrument would be invalid if a municipality's choice of whether or not to provide GAPS is correlated with child outcomes in the municipality. Firstly, however, from the local government's point of view, there are potentially large costs associated with not exactly meeting demand for slots in pre-school: having open slots is clearly costly in terms of teacher salaries and rent, which the municipality (by definition of open slots) is already committed to paying. On the other hand, providing too few slots causes dissatisfaction among municipality inhabitants and may affect voting behavior in the future. Secondly, remember that, as described in Section 2, prices as well as the maximum number of children per pre-school teacher in a municipality, the dominant quality parameter, are fixed within a given year. Municipalities can therefore not guarantee access to pre-school in a calendar year by lowering quality, and there are large fixed costs associated with establishing new pre-schools. Nor can parents, in the short run, be forced to cover the costs of a lower-than-predicted number of 
children enrolled in pre-school. Thus, conditional on municipality characteristics, we expect most of the variation in the provision of GAPS to stem from unexpected variations in demand, for example due to variations in cohort size.

Therefore, GAPS information provides us with potential variation in the take-up of pre-school, which is not a parental choice variable, and it has, arguably, no causal effect on child outcomes by itself. Of course, it would also invalidate our instrument if parents with more to gain from GAPS settle accordingly. Firstly, according to Simonsen (2006), there is very limited movement to and from municipalities providing advantageous child care policies. Secondly, there is municipality specific variation in child care policies over time. A couple can therefore not be sure that a municipality will not change its policy. This does not, of course, exclude the possibility that people settle because of child care policies, but it decreases the probability. Thirdly, it is unlikely that the child care policy is the main driver for settlement when compared to job opportunities and prices of real property. Furthermore, we condition on the number of siblings, which is expected to capture part of the expected gains from living in a municipality with GAPS.

We realize, of course, that child care policies are likely to be correlated with other municipality specific characteristics, which may affect, on the one hand, the parents' decision of where to live and, on the other hand, the municipality's capability of providing services in general. To counter this, our conditioning set includes municipality characteristics, see Section 5 above.

As pointed out earlier, treatment effects likely vary across individuals. For us to identify a meaningful parameter by using IV, we need an additional assumption, monotonicity, see Angrist, Imbens, and Rubin (1996) and Vytlacil (2002). This assumption implies that the instrument must affect individuals' behavior in one direction only. Because we have excluded the group of parents choosing home care from our analysis, we need an extended version of monotonicity, see Froelich (2004) for intuition and Appendix B for a formal proof. In particular, we need it to be the case that

1) parents who use pre-school under a GAPS regime must not use home care in the absence of GAPS,

2) parents who use pre-school in the absence of GAPS must use neither family day care nor home care under a GAPS regime, 
3) parents who use family day care under a GAPS regime must use neither pre-school nor home care in absence of GAPS,

4) parents who use family day care in the absence of GAPS must not use home care under a GAPS regime.

This essentially corresponds to monotonicity combined with independence of irrelevant alternatives assumed in a multinomial logit model. The information is summarized in Table 9 below along with the shares of our sample choosing each mode of care across the two regimes. A no indicates a state that must not occur under the extended version of monotonicity. We clearly see that more children are in pre-school under the GAPS regime, and, similarly, fewer children are in family day care. These trends along with the fact that the share of children in home care under the GAPS regime is similar to the share in home care under the no GAPS regime - the difference in raw means is four percentage points - offer tentative evidence that the monotonicity assumption is fulfilled. Furthermore, a Hausman-McFadden test, see Hausman and McFadden (1984), of IIA cannot reject the hypothesis that the coefficient to GAPS in the equation comparing family day care and preschool is the same in a multinomial logit including all alternatives and one in which we only include family day care and pre-school (t-statistic is 0.01$)$.

TABLE 9

STATES RUINING MONOTONICITY ${ }^{\text {a }}$

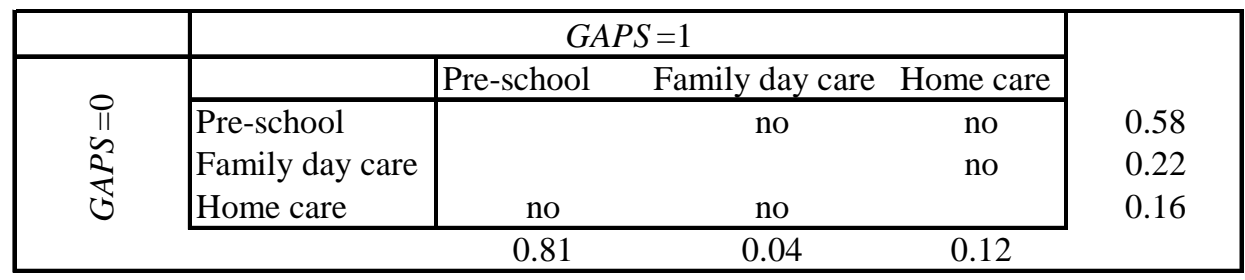

a 'no' indicates a state that must not occur under extended version of monotonicity

Given heterogeneous treatment effects and the monotonicity assumption, our IV procedure will estimate a local average treatment effect, not the average treatment effect:

$$
E\left[S D Q_{2}-S D Q_{1} \mid P S(G A P S)-P S(\text { no } G A P S)=1, H=0\right]
$$

i.e. the difference in child outcome with and without pre-school exposure for the group of children who would be enrolled in pre-school if they live in a municipality that guarantees access to pre- 
school but not otherwise. In other words, these are children of parents who are truly affected by a limited supply of slots. Clearly, some children may not enroll in pre-school under either regime, for example, if their parents are very selective in their choice of center or, along the same lines, if one of the parents has strong preferences for staying at home. Similarly, some children may always be enrolled in pre-school. This may occur by sheer luck (there is a probability that a child is always granted a slot). Always- and never-takers in the terminology of Angrist, Imbens, and Rubin (1996) do not contribute with any variation and therefore do not affect the parameter estimate.

Table 10 below shows the results from estimating (4') using 2SLS. Firstly, note that the instrument is highly significant in all regressions ${ }^{15}$ and works in the expected direction. We see that, qualitatively, the conclusions from our regression analysis are largely confirmed: pre-school participation significantly improves child outcomes for the entire sample, though only at the $10 \%$ level. Allowing these effects to vary across gender and according to mother's level of education demonstrates again that this is driven by the group of boys born to mothers with lower levels of education. Here, as opposed to the regression analysis, boys born to mothers with a high school degree or less seem unaffected by the choice of mode of care. The size of the parameter estimates is large compared to the OLS analyses from above. Remember, though, that we are identifying off of a different population, namely the group of compliers. In addition, all standard deviations are large.

\footnotetext{
${ }^{15}$ The t-statistic to the instrument is 11.00 in the regression using the entire sample and around 4 in all sub-population regressions. Staiger and Stock (1997) suggest as a rule of thumb that the t-statistic should be above $\sqrt{10}$.
} 
TABLE 10

IV COEFFICIENT ESTIMATES ${ }^{\mathrm{a}}$

OUTCOME: SDQ, MUNICIPALITY PROVIDED PRE-SCHOOL VS. FAMILY DAY CARE

\begin{tabular}{|c|c|c|c|c|}
\hline & First & tage & Pre- & ool \\
\hline & Coefficient & Std. Error & Coefficient & Std. Error \\
\hline Full Sample & 0.149 & 0.014 & -2.488 & 1.330 \\
\hline Girls of mothers with high school or below & 0.170 & 0.041 & -3.235 & 3.510 \\
\hline Boys of mothers with high school or below & 0.116 & 0.033 & 1.099 & 4.788 \\
\hline Girls of mothers with vocational degree & 0.159 & 0.035 & 1.623 & 3.173 \\
\hline Boys of mothers with vocational degree & 0.140 & 0.031 & -7.356 & 3.362 \\
\hline Girls of mothers with further education & 0.141 & 0.035 & 3.103 & 3.371 \\
\hline Boys of mothers with further education & 0.143 & 0.034 & -4.194 & 3.046 \\
\hline
\end{tabular}

${ }^{a}$ The conditioning set is the same as that of Table 4 . Bold coefficients are significant at the $5 \%$ level and italic indicates significance at the $10 \%$ level. All results robust to clustering at the municipality level.

\section{Sensitivity analyses}

One might hypothesize that labor markets in larger cities are different from those of the provinces, and that this may affect child care policies as well. From Table 8 above, it is clear that the county of Copenhagen that includes the Danish capital and largest city with 500,000 inhabitants has implemented different child care policies compared to the rest of the country. We therefore reestimate all models above excluding the county of Copenhagen. All results are robust to this. Secondly, dropping particularly disadvantaged children from the sample: children who have not been breast fed, children who have low birth weight, children who are physically disabled, immigrants and children brought up in single parent households, see e.g. Table 4 above, renders our results unchanged. Thirdly, since having older siblings (aged 4-6) enrolled in either family day care or pre-school allows a younger child to jump waiting lists, and one may worry that conditioning on sibling information do not sufficiently account for this, we exclude the part of the sample with 
siblings in the 4-6 age range. Again, parameter estimates are robust, though levels of significance are affected slightly because the sample is reduced considerably. Finally, we exclude lagged endogenous variables (parental employment after birth but before age three, number of prior care facilities, arranged for care at age six months, on waiting list at age six months) because they may introduce endogeneity bias. Our results are completely robust to this exercise. All results are available on request.

\section{Discussion}

This paper provides important new evidence on the effects on non-cognitive child outcomes of being enrolled in publicly provided care compared to home care. We find that, on average, participating in non-parental care is neutral compared to home care. Distinguishing between different types of non-parental care demonstrates, however, that pre-school and family day care result in very different outcomes compared to home care. Pre-school, where children are met with highly qualified staff in environments that allow for specialization of labor and where there is a much higher concentration of male staff, is found to be as good as home care no matter the gender and mother's level of education. Family day care, on the other hand, seems to reduce non-cognitive skills for boys born to mothers with low levels of education. Furthermore, increases in hours enrolled in both family day care and pre-school above the mean of 30 hours deteriorate child outcomes.

Our findings are not fully in line with the (rather sparse) literature on universal child care such as Baker et al. (2005). There are, however, good reasons for that. Firstly, Baker et al. (2005) evaluate the transition from one regime to another. As such, the study provides crucial information about the costs of switching from one regime to another, but the effects of a transition may not be a good indicator of the effects of the end-regime. For example, in the Baker et al. (2005) set-up, the number of slots is increased by $400 \%$ in three years, and though the staff:child ratios were only decreased slightly (1:8 to 1:10 for 4-5 year olds), the increase in slots generated huge demand for new staff and locations. Newly hired staff is likely to be less experienced and may also be drawn from the lower end of the skill distribution. Similarly, a large number of mothers are induced by the policy change to participate in the labor market. Presumably, this group consists of women with lower 
labor market outcomes and greater attachment to their homes (otherwise they would have participated before the policy was implemented). This group may not be representative of the population in general, and their experiences of the transition from being a stay-at-home mother to being an employee are therefore probably not representative either.

Interestingly, our conclusions regarding differences in the effects on behavioral skills of participating in pre-school compared to the more informal family day care for the group of children of low-skilled mothers resonate with the findings by Bernal and Keane (2006) who investigate cognitive skills. Of course, any gains from center-based care in terms cognitive and non-cognitive outcomes should be compared to adverse health outcomes associated with this type of care, see e.g. Gordon, Kaestner and Korenman (2007).

\section{References}

Andersen, A., M. Deding, and M. Lausten (2006), 'Starting School: the Effect of Early Childhood Factors on Child Well-being', The Danish National Centre for Social Research working paper.

Angrist, J. D., G. W. Imbens, and D. B. Rubin (1996), 'Identification of Causal Effects Using Instrumental Variables', Journal of the American Statistical Association 91, 444-455.

Baker, M., J. Gruber, and K. Milligan (2005): 'Universal Childcare, Maternal Labor Supply and Family Well-being’, NBER working paper \# 11832.

Behrman, J. R., Y. Cheng, and P. E. Todd (2004): 'Evaluating Pre-school Programs when Length of Exposure to the Program Varies: A Nonparametric Approach', Review of Economics and Statistics 86, 108-132.

Bernal, R. and M. Keane (2006): Child Care Choices and Children's Cognitive Achievement: The Case of Single Mothers, mimeo, Northwestern University. 
Blau, D. (1999): 'The Effect of Child Care Characteristics on Child Development', The Journal of Human Resources 34, 786-822.

Blau, D. and J. Currie (2006): 'Who is Minding the Kids', The Handbook of Education Economics, F. Welch and E. Hanushek eds, New York: North Holland

Blau, D. and A. P. Hagy (1998): “The Demand for Quality in Child Care”, The Journal of Political Economy 106, 104-146.

Camara, K. A. and G. Resnick (1988), 'Interparental Conflict and Cooperation: Factors Moderating Children’s Post-Divorce Adjustment', in E. M. Hetherington and J. Arasteh eds, Divorce, Single Parenting, and Step-Parenting on Children, Hillsdale, NJ: Erlbaum.

Cunha, F. and J. Heckman (2006), 'Formulating, Identifying and Estimating the Technology of Cognitive and Noncognitive Skill Formation, mimeo, University of Chicago.

Currie, J. (1994). 'Welfare and the Well-being of Children: The Relative Effectiveness of Cash and in-kind Transfers', in James M. Poterba eds, Tax Policy and the Economy Vol. 8, MIT Press.

Currie, J. and D. Thomas (1995), ‘Does Head Start Make a Difference?’, The American Economic Review 85, 341-364.

Currie, J. and D. Thomas (1999), 'Does Head Start Help Hispanic Children?', Journal of Public Economics 74, 235-262.

Currie, J. (2001), 'Early Childhood Intervention Programs: What Do We Know?', Journal of Economic Perspectives 15, 213-239.

Currie, J., E. Garces, and D. Thomas (2002), 'Longer Term Effects of Head Start', The American Economic Review 92, 999-1012. 
Currie J. and M. Stabile (forthcoming), 'Mental Health in Childhood and Human Capital: the Case of ADHD', Journal of Health Economics.

Datta Gupta, N., Smith, N., and M. Verner (forthcoming), 'The Impact of Nordic Countries' Family Friendly Policies on Employment, Wages and Children', Review of Economics of the Household.

Dee, T.S. (2006), 'The Why Chromosome: How a Teacher's Gender Affects Boys and Girls', Education Next, 4, 69-75.

Gregg, P., E. Washbrook, C. Propper, and S. Burgess (2005), 'The Effects of a Mother's Return to Work Decisions on Child Development in the UK', The Economic Journal (115), 48-80.

Goldin, C., L. F. Katz, and I. Kuziemko (2006), ‘The Homecoming of American College Women: the Reversal of the College Gender Gap’, NBER working paper \# 12139.

Goodman, R. (1997), ‘The Strengths and Difficulties Questionnaire: A Research Note.’ Journal of Child Psychology and Psychiatry 38, 581-586.

Gordon, R. A., R. Kaestner, and S. Korenman (2007), 'The Effects of Maternal Employment on Child Injuries and Infectious Disease’, Demography 44, 307-333.

Froelich, M. (2004), 'Programme Evaluation with Multiple Treatments', Journal of Economic Surveys 18, 181-224.

Hausman J. and D. McFadden (1984), 'Specification Tests for the Multinomial Logit', Econometrica 52, 1219-1240.

Heckman, J. J. and D. Masterov (2007), 'The Productivity Argument for Investing in Young Children’, NBER working paper \# 13016.

Heckman, J., J. Stixrud, and S. Urzua (forthcoming), 'The Effects of Cognitive and Noncognitive Abilities on Labor Market Outcomes and Social Behavior', Journal of Labor Economics. 
Knudsen, E. I., J. J. Heckman, J. L. Cameron, and J. P. Shonkoff (2006), 'Economic, Neurobiological and Behavioral Perspectives on Building America’s Future Workforce', NBER working paper \# 12298.

Lesesne, C.N., Vissner, S.N., and C.P. White (2003), ‘Attention-Deficit/Hyperactivity Disorder in School-Aged Children: Association with Maternal Mental Health and Use of Health Care Resources’, Pediatrics, 111 No. 5, 1232-1237.

Mott, F. L, L. Kowaleski-Jones and E. G. Menaghan (1997), 'Paternal Absence and Child Behavior: Does a Child's Gender Make a Difference?', Journal of Marriage and the Family 59, 103-118.

OECD (2001), ‘Early Childhood Education and Care Policy in Denmark.’ OECD country note.

Parcel, T. L. and E. G. Menaghan (1994), 'Early Parental Work, Family Social Capital, and Early Childhood Outcomes’, American Journal of Sociology 99, 972-1009.

Rosenbaum, P. R. (1987), 'The Consequences of Adjustment for a Concomitant Variable that has been Affected by the Treatment', Journal of the Royal Statistical Society Series A 147, 656-666.

Ruhm, C. (2004), 'Parental Employment and Child Cognitive Development', Journal of Human Resources 39, 155-192.

Segal, C. (forthcoming), 'Classroom Behavior’, Journal of Human Resources.

Segal, C. (2006), 'Misbehavior, Education, and Labor Market Outcomes', mimeo, Harvard Business School.

Simonsen, M. (2005), 'Availability and Price of High Quality Child Care and Female Employment', University of Aarhus working paper.

Stafford, F. (1987), ‘Women's Work, Sibling Competition, and Children's School Performance’, 
The American Economic Review 77, 972-980.

Staiger, D. and J. H. Stock (1997), 'Instrumental Variables Regression with Weak Instruments', Econometrica 65, 557-586.

Vytlacil, E. J. (2002), 'Independence, Monotonicity, and Latent Index Models: An Equivalence Result', Econometrica 70, 333-341.

Waldfogel, J., W.-J. Han, and J. Brooks-Gunn (2002), 'The Effects of Early Maternal Employment on Child Cognitive Development', Demography 39, 369-392. 


\title{
Appendix A
}

TABLE A1

LIST OF QUESTIONS USED TO

CONSTRUCT THE SDQ INDEX ${ }^{\mathrm{a}}$

\author{
Considerate of other people's feelings \\ Restless, overactive, cannot stay still for long \\ Often complains of headaches, stomach-aches or sickness \\ Shares readily with other childre, for example toys, treats, pencils \\ Often loses temper \\ Rather solitary, prefers to play alone \\ Generally well behaved, usually does what adults request \\ Many worries or often seems worried \\ Helpful if someone is hurt, upset or feeling ill \\ Constantly fidgeting or squirming \\ Has at least one good friend \\ Often fights with other children or bullies them \\ Often unhappy, depressed or tearful \\ Generally liked by other children \\ Easily distracted, concentration wanders \\ Nervous or clingy in new situations, easily loses confidence \\ Kind to younger children \\ Often lies or cheats \\ Picked on or bullied by other children \\ Often offers help to others (parents, teachers, other children) \\ Thinks things out before acting \\ Steals from home, school or elsewhere \\ Gets along better with adults than with other children \\ Many fears, easily scared \\ Good attention span, sees work through to the end
}

${ }^{a}$ Parents answer "not true", "somewhat true", or "certainly

true". See www.sdqinfo.com for the score sheets. 
TABLE A2 CTD.

MEANS OF SELECTED VARIABLES By MODE OF CARE ${ }^{\mathrm{a}}$

\begin{tabular}{|c|c|c|c|c|c|c|}
\hline & \multicolumn{2}{|c|}{ Home } & \multicolumn{2}{|c|}{ Pre-school } & \multicolumn{2}{|c|}{ Family Day Care } \\
\hline & Mean & Std. Dev. & Mean & Std. Dev. & Mean & Std. Dev. \\
\hline \multicolumn{7}{|l|}{ Child Care at age three: } \\
\hline Hours in non-parental care & 4.41 & 11.88 & 33.02 & 7.14 & 34.37 & 7.21 \\
\hline \# prior non-parental care facilities & 1.82 & 0.87 & 2.75 & 0.80 & 1.95 & 0.71 \\
\hline Pre-school teachers & 16.21 & 4.51 & 17.23 & 2.57 & 16.75 & 3.54 \\
\hline \multicolumn{7}{|l|}{ Child Characteristics: } \\
\hline Girl & 0.47 & 0.50 & 0.48 & 0.50 & 0.49 & 0.50 \\
\hline Birth month September & 0.37 & 0.48 & 0.39 & 0.49 & 0.34 & 0.47 \\
\hline Siblings & 1.04 & 1.03 & 0.77 & 0.83 & 0.81 & 0.85 \\
\hline Breast fed & 0.95 & 0.22 & 0.96 & 0.20 & 0.95 & 0.21 \\
\hline Birth weight (in 1000 grams) & 3.48 & 0.65 & 3.50 & 0.60 & 3.53 & 0.58 \\
\hline \# hospitalizations & 0.89 & 0.32 & 0.88 & 0.32 & 0.91 & 0.28 \\
\hline Physically disabled & 0.02 & 0.13 & 0.04 & 0.19 & 0.04 & 0.20 \\
\hline Full term birth & 0.45 & 0.50 & 0.45 & 0.50 & 0.46 & 0.50 \\
\hline Arranged for care & 0.29 & 0.45 & 0.32 & 0.47 & 0.34 & 0.47 \\
\hline Waiting list & 0.16 & 0.37 & 0.22 & 0.41 & 0.20 & 0.40 \\
\hline \multicolumn{7}{|l|}{ Mother's Characteristics: } \\
\hline Age & 27.84 & 4.90 & 28.37 & 4.61 & 28.23 & 4.34 \\
\hline Vocational degree & 0.33 & 0.47 & 0.37 & 0.48 & 0.42 & 0.49 \\
\hline Short further & 0.14 & 0.35 & 0.23 & 0.42 & 0.20 & 0.40 \\
\hline Long further & 0.04 & 0.21 & $\mathbf{0 . 0 7}$ & 0.26 & 0.05 & 0.21 \\
\hline Labor market experience & 6.19 & 5.88 & 7.37 & 5.81 & 7.15 & 5.50 \\
\hline Degree of year employed in 1996 & 0.40 & 0.35 & 0.55 & 0.35 & 0.57 & 0.34 \\
\hline Degree of year employed in 1997 & 0.44 & 0.42 & 0.64 & 0.40 & 0.65 & 0.39 \\
\hline Degree of year employed in 1998 & 0.46 & 0.43 & 0.67 & -0.39 & 0.70 & 0.38 \\
\hline Smoker & 0.34 & 0.47 & 0.30 & 0.46 & 0.31 & 0.46 \\
\hline Single & 0.06 & 0.24 & 0.04 & 0.19 & 0.02 & 0.15 \\
\hline Non-native speaker & 0.03 & 0.17 & 0.02 & 0.13 & $\mathbf{0 . 0 0}$ & 0.07 \\
\hline Postpartum depression & 0.01 & 0.11 & 0.01 & 0.10 & 0.01 & 0.10 \\
\hline Income $1996(1,000 \mathrm{DKK})$ & 111 & 33 & 118 & 35 & 119 & 36 \\
\hline \multicolumn{7}{|l|}{ Father's Characteristics: } \\
\hline Vocational degree & 0.42 & 0.49 & 0.43 & 0.50 & 0.50 & 0.50 \\
\hline Short further & 0.11 & 0.32 & 0.15 & 0.36 & 0.13 & 0.33 \\
\hline Long further & 0.06 & 0.24 & 0.10 & 0.30 & 0.06 & 0.23 \\
\hline Labor market experience & 10.48 & 5.79 & 11.11 & 5.73 & 11.35 & 5.41 \\
\hline Leave & 0.13 & 0.34 & 0.25 & 0.43 & 0.19 & 0.39 \\
\hline
\end{tabular}

${ }^{\mathrm{a}}$ Bold coefficients indicate that means are significantly different (at the $5 \%$ level) from those of home care.

Table continues on next page 
TABLE A2 CTD.

MEANS OF SELECTED VARIABLES By MODE OF CARE ${ }^{\mathrm{a}}$

\begin{tabular}{lcccccc}
\hline \hline Municipality and Regional Characteristics: & & & & & \\
Region 1 & 0.20 & 0.40 & 0.23 & 0.42 & $\mathbf{0 . 0 3}$ & 0.17 \\
Region 2 & 0.07 & 0.26 & $\mathbf{0 . 1 3}$ & 0.33 & 0.05 & 0.22 \\
Region 3 & 0.12 & 0.33 & $\mathbf{0 . 1 0}$ & 0.29 & $\mathbf{0 . 0 8}$ & 0.27 \\
Region 4 & 0.10 & 0.29 & 0.08 & 0.27 & $\mathbf{0 . 1 4}$ & 0.35 \\
Region 5 & 0.09 & 0.28 & 0.10 & 0.31 & 0.09 & 0.29 \\
Region 6 & 0.12 & 0.32 & 0.11 & 0.31 & $\mathbf{0 . 2 3}$ & 0.42 \\
Region 7 & 0.21 & 0.41 & $\mathbf{0 . 1 7}$ & 0.37 & 0.23 & 0.42 \\
Region 8 & 0.10 & 0.30 & 0.10 & 0.30 & $\mathbf{0 . 1 4}$ & 0.35 \\
Single parent children & 13.19 & 4.42 & $\mathbf{1 4 . 2 7}$ & 4.26 & $\mathbf{1 1 . 4 8}$ & 3.32 \\
Asylum seekers & 23 & 65 & 20 & 72 & 26 & 78 \\
Third world immigrants & 288 & 219 & $\mathbf{3 2 8}$ & 218 & $\mathbf{2 1 5}$ & 143 \\
Social Democrats & 0.57 & 0.50 & $\mathbf{0 . 6 3}$ & 0.48 & 0.57 & 0.50 \\
Conservatives & 0.05 & 0.21 & $\mathbf{0 . 0 9}$ & 0.28 & $\mathbf{0 . 0 2}$ & 0.14 \\
Child families & 0.29 & 0.09 & $\mathbf{0 . 4 0}$ & 1.61 & $\mathbf{0 . 3 3}$ & 0.06 \\
\hline
\end{tabular}

${ }^{\mathrm{a}}$ Bold coefficients indicate that means are significantly different (at the $5 \%$ level) from those of home care.

\section{Appendix B}

This appendix extends the monotonicity assumption of Angrist and Imbens (1994) to cover the case with three treatments: home, $H$, family day care, FC, and pre-school, PS. Specifically, we are interested in uncovering the following LATE ((4) from Section 6):

$$
E\left[S D Q_{2}-S D Q_{1} \mid P S(G A P S)-P S(\text { no GAPS })=1, H=0\right] .
$$

To establish the extended version of monotonicity assumption, the following indicators turn out to be useful:

$$
\begin{aligned}
& D^{1}= \begin{cases}0 & D C \\
1 & P S\end{cases}
\end{aligned}
$$

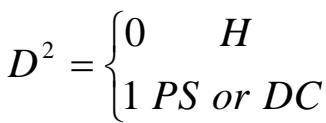

Our instrument is the binary variable guaranteed access to pre-school, GAPS. As in Angrist and Imbens (1994), we allow the outcomes of $D^{1}$ and $D^{2}$ to depend on the realization of GAPS: 
$D^{1}(G A P S)$ and $D^{2}$ (GAPS). Similarly, child outcome $S D Q$ is (on the outset) allowed to depend on $D^{1}, D^{2}$, and $G A P S: S D Q\left(D^{1}, D^{2}, G A P S\right)$.

We assume that SUTVA and random assignment holds and make the following exclusion restriction:

$$
S D Q\left(D^{1}, D^{2}, G A P S\right)=S D Q\left(D^{1}, D^{2}, G A P S^{\prime}\right) \quad \forall \text { GAPS, GAPS' and } \forall D^{1}, D^{2} .
$$

Thus,

$$
S D Q\left(D^{1}, D^{2}\right)=S D Q\left(D^{1}, D^{2}, G A P S^{\prime}\right)=S D Q\left(D^{1}, D^{2}, G A P S\right) .
$$

Furthermore, we assume a nonzero average causal effect of GAPS on $D^{1}$ :

$$
E\left[D^{1}(1)-D^{1}(0)\right] \neq 0 .
$$

Finally, we maintain the monotonicity assumption from Angrist and Imbens (1994) that

$$
D^{1}(0) \leq D^{1}(1)
$$

for all individuals in the population and extend with the assumption that

$D^{2}(0)=D^{2}(1)=1$

for all individuals for whom we observe $D^{2}=1$.

Now we can show that the IV estimand

$$
\frac{E\left[S D Q_{i}\left(1, D_{i}^{1}(1), D_{i}^{2}(1)\right)-S D Q_{i}\left(0, D_{i}^{1}(0), D_{i}^{2}(0)\right) \mid D_{i}^{2}=1\right]}{E\left[D_{i}^{1}(1)-D_{i}^{1}(0) \mid D_{i}^{2}=1\right]}
$$

converges towards our parameter of interest from above. Consider first the nominator: 


$$
\begin{aligned}
& {\left[S D Q_{i}\left(1, D_{i}^{1}(1), D_{i}^{2}(1)\right)-S D Q_{i}\left(0, D_{i}^{1}(0), D_{i}^{2}(0)\right) \mid D_{i}^{2}=1\right]} \\
& =\left[S D Q_{i}\left(D_{i}^{1}(1), D_{i}^{2}(1)\right)-S D Q_{i}\left(D_{i}^{1}(0), D_{i}^{2}(0)\right) \mid D_{i}^{2}=1\right] \\
& =\left\{S D Q_{i}(1,1) D_{i}^{1}(1) D_{i}^{2}(1)+S D Q_{i}(0,1)\left[1-D_{i}^{1}(1)\right] D_{i}^{2}(1) \mid D_{i}^{2}=1\right\} \\
& -\left\{S D Q_{i}(1,1) D_{i}^{1}(0) D_{i}^{2}(0)+S D Q_{i}(0,1)\left[1-D_{i}^{1}(0)\right] D_{i}^{2}(0) \mid D_{i}^{2}=1\right\} \\
& =\left\{\left[S D Q_{i}(1,1)-S D Q_{i}(0,1)\right]\left[D_{i}^{1}(1) D_{i}^{2}(1)-D_{i}^{1}(0) D_{i}^{2}(0)\right] \mid D_{i}^{2}=1\right\} \\
& -\left\{S D Q_{i}(0,1)\left[D_{i}^{2}(1)-D_{i}^{2}(0)\right] \mid D_{i}^{2}=1\right\} \\
& =\left\{\left[S D Q_{i}(1,1)-S D Q_{i}(0,1)\right]\left[D_{i}^{1}(1)-D_{i}^{1}(0)\right] \mid D_{i}^{2}=1\right\}
\end{aligned}
$$

The first step uses our exclusion restriction, while the last employs our extension to the monotonicity assumption. Using standard monotonicity, we get

$$
\begin{aligned}
& E\left[\left\{\left[S D Q_{i}(1,1)-S D Q_{i}(0,1)\right]\left[D_{i}^{1}(1)-D_{i}^{1}(0)\right] \mid D_{i}^{2}=1\right\}\right] \\
& =E\left[S D Q_{i}(1,1)-S D Q_{i}(0,1) \mid D_{i}^{1}(1)-D_{i}^{1}(0)=1, D_{i}^{2}=1\right] P\left[D_{i}^{1}(1)-D_{i}^{1}(0)=1 \mid D_{i}^{2}=1\right]
\end{aligned}
$$

It is straightforward to show that

$$
E\left[D_{i}^{1}(1)-D_{i}^{1}(0) \mid D_{i}^{2}=1\right]=P\left[D_{i}^{1}(1)-D_{i}^{1}(0) \mid D_{i}^{2}=1\right],
$$

which gives us our result. 